\section{Water Relations of Leaves of 'Sonia' Rose Plants Grown in Soilless Greenhouse Conditions}

\author{
L. Urban, R. Brun, and P. Pyrrha \\ Unité de Recherche Intégrée en Horticulture, Institut National de la Recherche \\ Agronomique, Sophia-Antipolis, 06410 Biot, France
}

Additional index words. Rosa hybrids, elastic modulus, greenhouse culture, osmotic potential, turgor loss point

\begin{abstract}
Rose plants (Rosa hybrids Cv. Sonia) were grown in rockwool in two heated greenhouses: one with relative humidity $(\mathrm{RH})$ control $(\mathrm{RH}>\mathbf{7 0 \%})$ provided by high-pressure mist, the other protected against overheating using a movable screen without RH control. Two electrical conductivity (EC) rates were applied: high (EC of drainage water $\approx 3.8 \mathrm{mS} \cdot \mathrm{cm}^{-1}$ ) and low $\left(\right.$ EC of drainage water $\approx 1.8 \mathrm{mS} \cdot \mathrm{cm}^{-1}$ ). Under these conditions, water deficit in plants was due mainly to climate, and not to EC. The relative water content of sample leaves picked at noon $\left(\mathrm{RWC}_{\text {noon }}\right)$ was one to two percentage points higher in the greenhouse with $\mathrm{RH}$ control and dropped by $6 \%$ to $7 \%$ in summer. $\mathrm{RWC}_{\text {noon }}$ was unaffected by differences in EC. The average elastic modulus (E) and the relative water content threshold for turgor loss $\left(\mathrm{RWC}^{0}\right)$ were reduced in the greenhouse with $\mathrm{RH}$ control. $\varepsilon$ was increased in the high EC treatment, but $\mathrm{RWC}^{0}$ remained unaffected.
\end{abstract}

Cultivation of greenhouse roses in rockwool is expanding rapidly. But very little is known about water relations and more generally about woody plant behavior over time in soilless greenhouse conditions. Water stress in plants results from both reduced soil water potential, which usually builds up progressively over a period of time, and fluctuations in evaporation rate due to daily changes in net radiation and humidity (Morgan, 1984). In soilless conditions, substrate water potential may also vary on a daily basis. The volume for water retention in artificial substrates is low compared to that of natural soils (Rivière and Nicolas, 1987). Thus, water availability in the root medium can vary dramatically during the day if watering is insufficient. Moreover, plants take up water at a faster rate than mineral elements, thus contributing to an increase in salinity in the root substrate. This is particularly true when transpiration is high and when the concentration of the supplied nutrient solution is high compared to that taken up by the plants. Our aim was to further our understanding of rose leaf water relations as they maybe affected by seasonal and cultural variations, with water supply closely meeting climatic demand and salinity being kept under control.

\section{Materials and Methods}

Two electrical conductivity (EC) levels of the nutrient solution were compared, one low $\left(\mathrm{EC}=1.8 \mathrm{mS} \cdot \mathrm{cm}^{-1}\right)$ and one high $(\mathrm{EC}=3.8$

Received for publication 7 June 1993.Accepted for publication 3Nov. 1993. We thank S. Adamowicz, A. Coudret, P. Cruiziat, R. Habib, and A. Jaffrin for their helpful comments.The cost of publishing this paper was defrayed in part by the payment of page charges.Under postal regulations, this paper thereforemustbehereby marked advertisement solely to indicatethis fact.
$\left.\mathrm{mS} \cdot \mathrm{m}^{-1}\right)$. The low EC rate was chosen following the recommendations of Brun and Tramier (1988) for rose cultivation in rockwool. The high EC rate was $>3.3 \mathrm{mS} \cdot \mathrm{cm}^{-1}$, an EC value that De Kreij and Van den Berg ( 1990) found to have a negative effect on the production of 'Sonia' rose plants grown in rockwool. The effect of relative humidity $(\mathrm{RH})$ control on rose water relations was also investigated by comparing two greenhouses, one shaded and one with high-pressure mist (HPM).

The experiment was conducted during Spring 1991 and Winter 1992 on Rosa hybrids CV. Sonia plants. Cuttings were rooted in rockwool cubes on 2 Apr. 1990, then planted on rockwool slabs on 10 May at seven plants per slab $\left(7.5\right.$ plants $\left./ \mathrm{m}^{2}\right)$. Rockwool slabs measured $100 \mathrm{~cm}$ long $\times 20 \mathrm{~cm}$ wide $\times 7.5 \mathrm{~cm}$ deep

Air temperature setpoints were maintained in both greenhouses with a standard climatecontrol computer. The prescribed daytime temperature for ventilation was set at $22 \mathrm{C}$, with a nighttime minimum of $13 \mathrm{C}$ throughout the season. Climatic conditions were continuously monitored and recorded by dataloggers equipped with pyranometers (LI-200SZ; LICOR, Cunow, Cergy St. Christopher, France) for solar radiation measurements; platinum resistance elements (PG 14825; Jumorégulation, Metz, France) for temperature measurements; and laboratory-made dry and wet bulb hygrometers ( $1 \%$ accuracy), ventilated and protected against radiation, for $\mathrm{RH}$ measurements. Greenhouses were not replicated, but homogeneity of the plant material selected for measurements was checked beforehand, and special attention was paid to limit air temperature and solar radiation discrepancies between both greenhouses (Table 1). In the shaded greenhouse (LS16 screen, Ludwig Svensson, Hass Energieschirme, Puderbach-Niederdreis, Germany; this screen stops $\approx 50 \%$ incident solar radiation), shading was started as soon as global radiation reached $800 \mathrm{~W} \cdot \mathrm{m}^{-2}$ and air temperature rose above 30C. In the greenhouse with RH control, fogging automatically started when RH dropped below $65 \%$ to $70 \%$. The high levels of RH were achieved with a commercial HPM system (The fog system; Dutrie, Steenwerck, France) delivering droplets of $<10 \mu \mathrm{m}$ in diameter, at a rate of 7 liters $\cdot \mathrm{h}^{-1} \cdot \mathrm{m}^{-2}$. Mean and minimal daytime $\mathrm{RH}$ values (obtained at noon) were significantly higher in the misted greenhouse, proving that HPM was effective in increasing $\mathrm{RH}$, especially around noon (Table 1).

Fertilization followed the recommendations of Brun and Tramier ( 1988), with $\mathrm{pH}$ set at 5.6. At $\mathrm{EC}=1.8 \mathrm{mS} \cdot \mathrm{cm}^{-1}$, the composition of the supplied nutrient solution was (in $\left.\mathrm{mg} \cdot \mathrm{liter}^{-1}\right): \mathrm{NO}_{3}, 154 ; \mathrm{NH}_{4}^{+}, 28 ; \mathrm{HPO}_{4}^{2-}, 96 ; \mathrm{K}^{+}$, $195 ; \mathrm{Ca}^{2+}, 160 ; \mathrm{Mg}^{2+}, 2 ; \mathrm{SO}_{4}^{2-}, 192$. For both $\mathrm{EC}$ values, the concentrations of the major elements were changed proportionally. Iron and microelements were provided by a commercial solution (Kanieltra 6 Fe; Hydro-Azote, Neuilly/Seine, France) at a constant concentration of 0.1 liter $\cdot \mathrm{m}^{-3}$. Irrigation was scheduled using a standard computer equipped with a Kipp and Zonen solar energy sensor (System 9; Indal-Eral, Mallemort, France). Irrigation was triggered for each $280-\mathrm{J} \cdot \mathrm{cm}^{-2}$ increment of external horizontal solar energy. Irrigation delivered $100 \%$ of the expected maximum evapotranspiration (De Villèle, 1972). Cumulative drainage over $24 \mathrm{~h}$ was at least $40 \%$ of the supplied volume. The method devised to monitor EC of the drainage water has been described by Brun et al. ( 1993). The plots (56 plants/plot) were distributed according to a block-trial design with four replications for each of the two EC treatments.

The mean 24-h value of drainage water EC $\left(\mathrm{EC}_{\text {drainge }}\right)$ was recorded daily for each plot of each EC treatment. Drainage water osmotic potentials $\left(\Psi_{\text {drainage }}\right)$ were calculated using the conversion factor given by Ayers and Westcot ( 1975): $\Psi_{\text {drainage }}(\mathrm{MPa})=00.036 \cdot \mathrm{EC}_{\text {drain }}$ $\left(\mathrm{mS} \cdot \mathrm{cm}-{ }^{-}\right)$. The predawn water potential $\left(\Psi_{\text {predawn }}\right)$ was determined on eight leaves per salinity treatment once a week. Leaves used for $\Psi_{\text {predawn }}$ measurements were placed, immediately after excision, in a portable pressure chamber having a precision of $0.01 \mathrm{MPa}$ (made by Institut National de la Recherche Agronomique-Station de Bioclimatologie de Clermont-Ferrand). The rate of increase or decrease of the pressure in the chamber was kept below $0.005 \mathrm{MPa} \cdot \mathrm{s}^{-1}$. Measurements were repeated several times on the same leaf.

The relative water content of eight leaves per EC treatment was measured each day at $1200 \mathrm{HR}\left(\mathrm{RWC}_{\text {noon }}\right)$. At night, plants recover from the water loss experienced during the day and reach an equilibrium with the soil. Thus, $\Psi_{\text {predawn }}$. can be considered as a measure of the plants' minimum water stress arising from progressive water depletion in the soil (Running, 1976), while $\mathrm{RWC}_{\text {noon }}$ measures the plants maximum water stress resulting from water depletion in the soil and daily increase in water vapor pressure deficit in the atmosphere, which generally peaks around noon. RWC is ex- 
Table 1. Climatic data for the shaded and the misted greenhouses (HPM).

\begin{tabular}{|c|c|c|c|c|c|c|}
\hline \multirow[b]{2}{*}{ Measurement } & \multirow[b]{2}{*}{ Greenhouse } & \multicolumn{5}{|c|}{ Period of measurement ${ }^{2}$} \\
\hline & & 1 & 2 & 3 & 4 & 5 \\
\hline \multicolumn{7}{|l|}{ Mean daytime } \\
\hline air temperature & Shaded & $21.5 \pm 0.6^{y}$ & $25.6 \pm 0.2$ & $26.1 \pm 0.3$ & $23.6 \pm 0.4$ & $20.1 \pm 0.3$ \\
\hline$\left({ }^{\circ} \mathrm{C}\right)$ & HPM & $21.8 \pm 0.6$ & $25.1 \pm 0.4$ & $27.4 \pm 0.4$ & $24.3 \pm 0.5$ & $20.6 \pm 0.3$ \\
\hline \multicolumn{7}{|l|}{ Maximal daytime } \\
\hline air temperature & Shaded & $28.2 \pm 0.4$ & $29.3 \pm 0.6$ & $33.3 \pm 0.5$ & $28.8 \pm 0.6$ & $25.7 \pm 0$ \\
\hline$\left({ }^{\circ} \mathrm{C}\right)$ & HPM & $28.7 \pm 0.4$ & $29.9 \pm 0.3$ & $30.6 \pm 0.3$ & $28.2 \pm 0.5$ & $25.3 \pm 0.4$ \\
\hline \multicolumn{7}{|l|}{ Mean daytime } \\
\hline air relative & Shaded & $69 \pm 2$ & $72 \pm 2$ & $61 \pm 3$ & $79 \pm 4$ & $79 \pm 1$ \\
\hline humidity (\%) & HPM & $82 \pm 1$ & $85 \pm 2$ & $73 \pm 1$ & $79 \pm 5$ & $84 \pm 1$ \\
\hline \multicolumn{7}{|l|}{ Minimal daytime } \\
\hline air relative & Shaded & $45 \pm 3$ & $53 \pm 4$ & $45 \pm 5$ & $65 \pm 3$ & $66 \pm 4$ \\
\hline humidity (\%) & HPM & $71 \pm 1$ & $74 \pm 3$ & $68 \pm 3$ & $73 \pm 2$ & $73 \pm 4$ \\
\hline \multicolumn{7}{|l|}{ Mean cumulated } \\
\hline solar radiation ${ }^{x}$ & Shaded & $1512 \pm 171$ & $2203 \pm 91$ & $2055 \pm 88$ & $1209 \pm 91$ & $440 \pm 37$ \\
\hline$\left(\mathrm{J} \cdot \mathrm{cm}^{-2}\right)$ & HPM & $1553 \pm 168$ & $2242 \pm 138$ & $1880 \pm 84$ & $1215 \pm 91$ & $430 \pm 34$ \\
\hline \multicolumn{7}{|l|}{ Maximal solar } \\
\hline radiation & Shaded & $747 \pm 42$ & $829 \pm 50$ & $821 \pm 27$ & $564 \pm 34$ & $245 \pm 14$ \\
\hline$\left(W \cdot m^{-2}\right)$ & HPM & $728 \pm 42$ & $800 \pm 46$ & $782 \pm 103$ & $579 \pm 35$ & $262 \pm 15$ \\
\hline
\end{tabular}

DData are from five periods: 1) 29 Apr. to 17 May; 2) 12-27 June; 3) 15-30 July; 4) 16 Sept. to 1 Oct.; 5) 13-28 Jan.

Y Values are means \pm standard deviations.

xSolar radiation includes $\approx 50 \%$ photosynthetically active radiation.

pressed as follows: $\mathrm{RWC}=100 \cdot(\mathrm{FW}-\mathrm{DW}) /$ (SW - DW), where FW, DW, and SW represent fresh weight, dry weight, and saturated fresh weight of the leaves, respectively.

Data were collected for five periods: 29 Apr. to 17 May 1991, 12-27 June 1991,15-30 July 1991, 16 Sept. to 1 Oct. 1991, and 13-28 Jan. 1992. Pressure-volume analysis was performed on young mature leaves according to the method described by Urban et al. (1993).E, the mean volumetric elasticity modulus, was calculated following Zimmerman (1978) and Jones and Turner (1980): $: \varepsilon=\left(\Psi_{\mathrm{p}}{ }^{100}-\Psi_{\mathrm{p}}{ }^{0}\right) \cdot(1-$ $\left.\mathrm{A}_{\mathrm{p}}^{100}\right) /\left(1-\mathrm{RWC}^{0}\right)$, where exponents $\mathrm{O}$ and 100 are relative to values at turgor loss and full turgor, respectively $\Psi_{\mathrm{p}}$ represents the turgor and $\mathrm{A}_{\mathrm{p}}$ the nonosmotic water fraction.

Differences in $\Psi_{\pi}^{0}, \Psi_{\pi}^{100}, \varepsilon, \quad \mathrm{RWC}^{0}$, and $\mathrm{RWC}_{\text {noon }}$ were treated by analysis of variance (ANOVA) at $P=0.05$ (two RH treatments, two EC treatments, four blocks per greenhouse, five periods).

\section{Results and Discussion}

$\Psi_{\text {drainge }}$ figures (Fig. 1) are mean values over $24 \mathrm{~h}$ and do not give more than indirect and delayed information about the substrate water potential. However, we can safely consider that water remained fully available for uptake by the roots for short-term (day) and long-term periods as shown by the following observations:

$\Psi_{\text {predawn }}$ can be considered to be a measure of the water potential of the substrate, at the end of the night, at a moment when it is presumably the highest. $\Psi_{\text {predawn }}$ (Fig. 2) was close to the expected $\Psi_{\text {drainage }}$ (Fig. 1) for each salinity treatment. If the substrate water potential had ever decreased during daytime, then $\Psi_{\text {drainage }}$ would have been lower (more negative) than $\Psi_{\text {predawn }}$. But this obviously did not occur. Moreover, on selected days, EC measurements were repeatedly made on the nutrient solution taken from the substrate by syringe. They did not show any significant shift.
$\mathrm{RWC}_{\text {noon }}$ values of the third period are the result of the low RH and high air temperature values recorded during the same period (Table 1). Measurements of $\mathrm{RWC}_{\text {noon }}$ had mean values ranging from $88 \%$ to $96 \%$ in the misted greenhouse and from $87 \%$ to $94 \%$ in the shaded greenhouse (Fig. 3). Seasonal changes in $\mathrm{R} \mathrm{W} \mathrm{C}_{\text {noon }}$ far outweigh those due to $\mathrm{RH}$ control; seasonal change accounted for a 6- to 7point variation in $\mathrm{RWC}_{\text {noon}}$, while $\mathrm{RH}$ control helpedRWCnoon increase by just 1 to 2 points (Fig, 3).

Adaptative responses can be revealed by comparing stressed plants to unstressed plants. With this purpose in mind, we compared, in our trial, rose plants grown at relatively high $\mathrm{EC}$ to plants grown at low EC, and rose plants grown at low RH (shaded greenhouse) to plant grown at high RH (greenhouse with HPM), respectively.

$\Psi_{\pi}^{0}$ and $\Psi_{\pi}$ were not significantly reduced by the high EC or by the absence of RH control (Table 2). Radin (1983) has indicated that osmotic adjustment is evidenced by a downward shift in $\Psi_{\pi}$ at all RWC. Thus, we can conclude-that no osmotic adjustment due to high EC or absence of RH control was revealed in our trial. The observations of Hinckley et al. (1980) and Joly and Zaerr (1987) suggest that osmotic adjustment is not as great in woody shrubs and trees as in herbaceous plants. The general lack of effect of high EC on $\Psi_{\pi}$ may also be due to leaf maturity. Morgan (1980) observed a higher degree of osmotic adjustment in the apex and expanding leaves of wheat (Triticum aestivum L.) than in fully expanded leaves. The effect of our protocol must also be considered. Possibly, measurements performed on leaves picked at dawn did not reveal osmotic adjustment occurring in the daytime. But considering the evidence of osmotic adjustment in mature rose leaves picked early in the morning (Augé et al., 1986, 1990), we feel this lack of response is more likely due to the weak stress undergone by the which appears to have been the most stressful for the plants. It seems obvious that the low

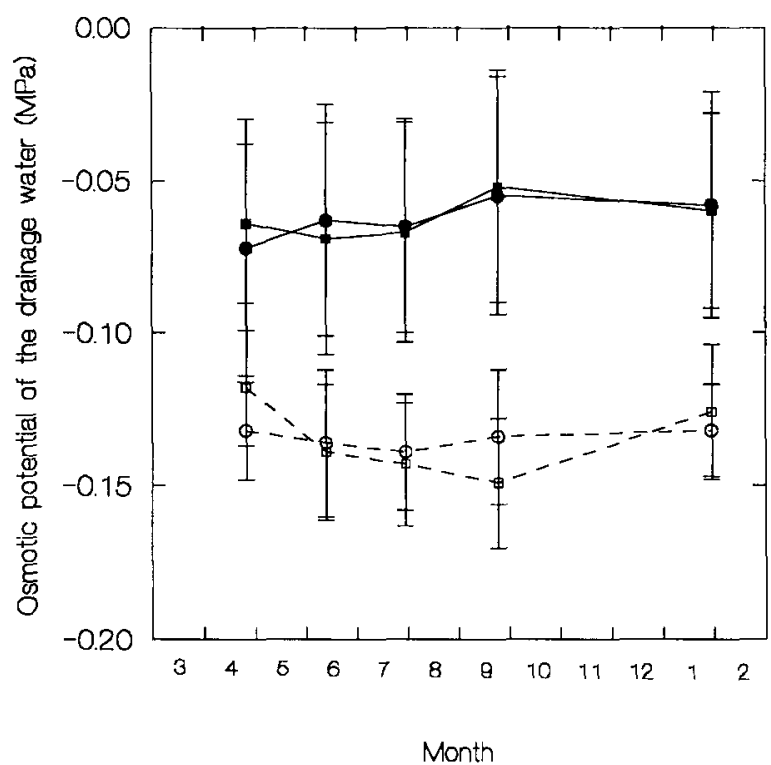

Fig. 1. Osmotic potential of the drainage water for low-electrical-conductivity (EC) solution: ( - shaded greenhouse, (- - ) high-pressure mist; for high EC solution: (-O- ) shaded greenhouse, $(-\square-)$ high-pressure mist, at five periods. Vertical bars on data points represent standard deviations. 


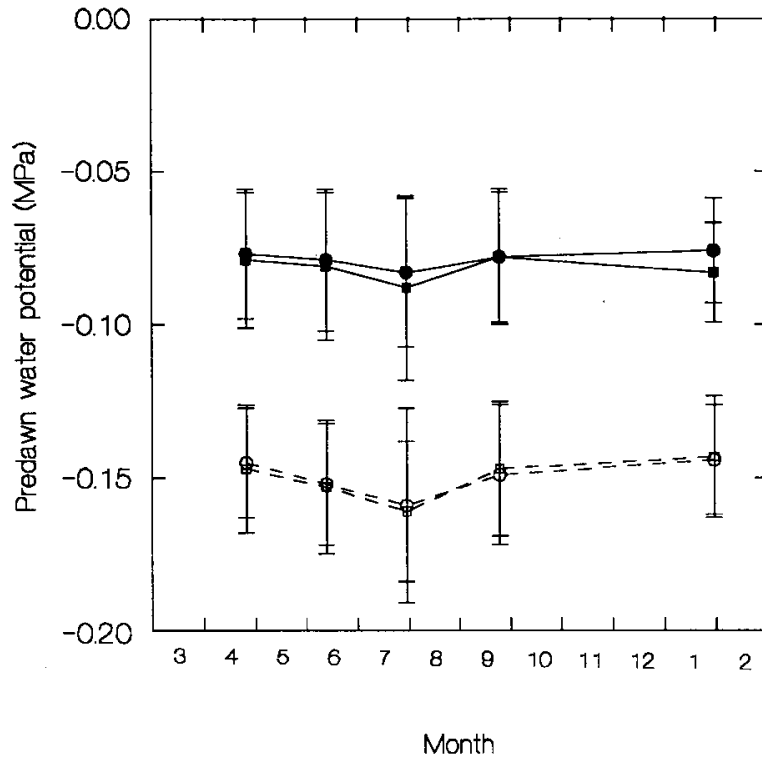

Fig. 2. Predawn water potential for low-electrical-conductivity (EC) solution: ( (- Wigh-pressure mist; for high EC solution: (-O-) shaded greenhouse, (mist, at five periods. Vertical bars on data points represent standard deviations.

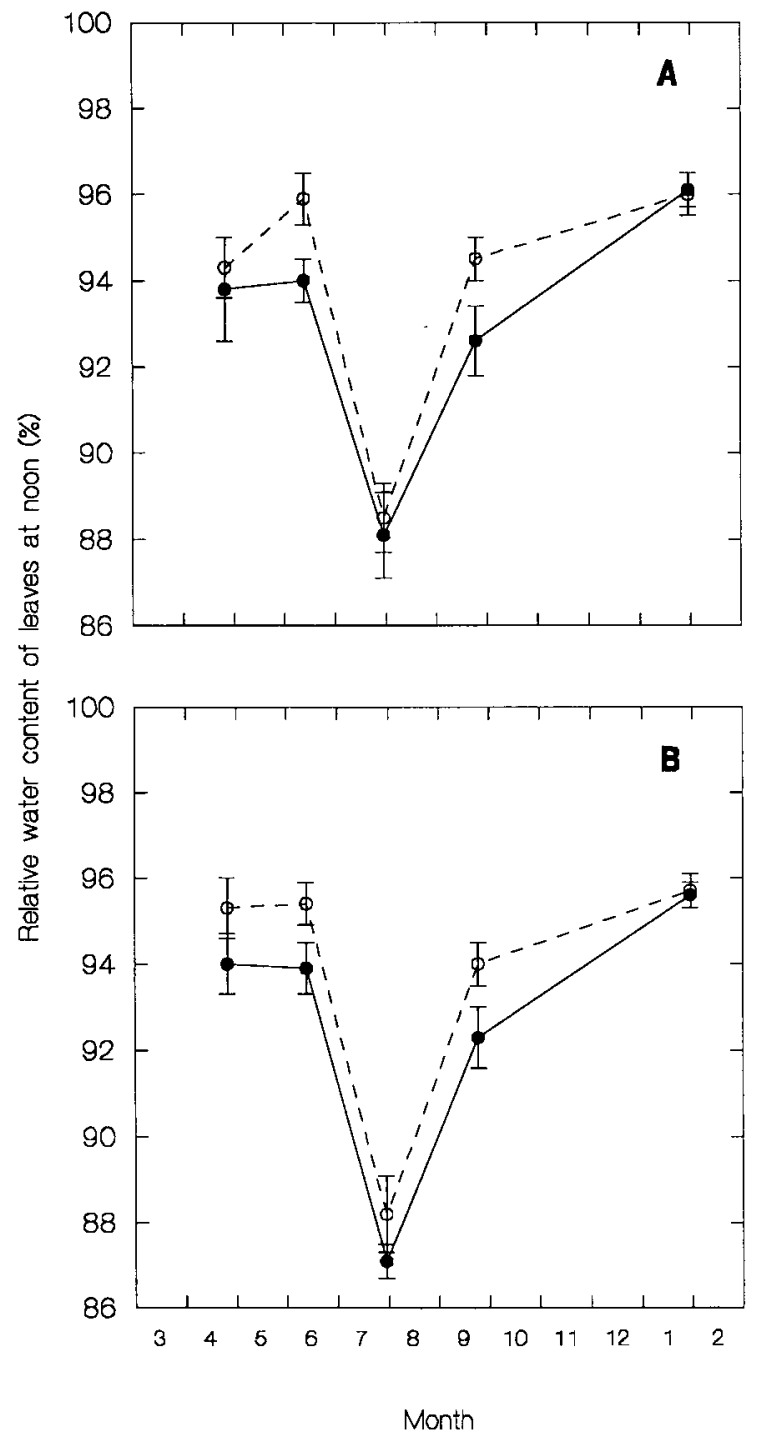

Fig. 3. Relative water content of leaves excised at noon $\left(\mathrm{RWC}_{\text {noon }}\right)$ for $(\mathbf{A})$ low-electrical-conductivity $(\mathrm{EC})$ solution and (B) high EC: (- - ) shaded greenhouse, ( $\left.-\bigcirc_{-}\right)$high-pressure mist, at five periods. Vertical bars on data points represent standard deviations. rose plants in our growing conditions. Turner and Jones (1980) emphasized the fact that osmotic adjustment depends on degree of stress.

Other adaptive responses like increases in $\mathrm{E}$, which also have been demonstrated to occur in leaves of drought-stressed rose plants (Augé et al., 1987, 1990), occurred as a consequence of the high EC and the absence of RH control (Table 2). An increase in $\mathrm{E}$ (corresponding to a decrease in tissue elasticity) reduces the quantity of water loss required for turgor loss, i.e., it induces an increase in $\mathrm{RWC}^{0}$. Most plants decrease $\mathrm{E}$ when submitted to a water or salinity stress. This change may provide them with resistance to short-term water deficits (Zimmerman, 1978). However, Cheung et al. (1975) suggested that an increase in $\varepsilon$ as a consequence of drought may also confer physiological advantages by reducing turgor and $\mathrm{Y}$, which favors water uptake from drying soil. In our conditions, an increase in $\mathrm{E}$ induced by the high EC did not prove sufficient to significantly increase $\mathrm{RWC}^{0}$ because there was a simultaneous decrease in $\Psi_{\pi}$ (Table 2). This decrease, although nonsignificant, had the opposite-effect, i.e., it reduced RWC $^{\circ}$ (Radin, 1983). In contrast, the intensity of observed turgor adjustment $(0.3$ to $0.5 \mathrm{MPa})$ was slight when compared to $\mathrm{E}$ differences observed by Augé et al. (1987, 1990), which ranged from 1 to $2 \mathrm{MPa}$. On the contrary, the absence of $\mathrm{RH}$ control was associated to an increase in\& of 0.5 to $0.7 \mathrm{MPa}$, itself associated with a significant increase in $\mathrm{RWC}^{\circ}$ (Table 2).

In conclusion, a drainage water EC of 3.8 $\mathrm{mS} \cdot \mathrm{cm}^{-1}$ is probably not stressful for rose plants grown in rockwool, provided that care is taken to avoid EC deviations by monitoring inlet solution concentration daily. The negative effect of high EC on rose production observed by De Kreij and Van den Berg ( 1990) might be attributed to uncontrolled daytime increases in EC, which passed unnoticed by considering only average values of drainage water EC.

HPM has two positive effects when compared to shading: it helped to reduce the imposed water stress, i.e., to increase $\mathrm{RWC}_{\text {noon }}$, and to increase the water loss required before turgor loss, i.e., to decrease RWC ${ }^{0}$. Nonetheless, HPM did not prove sufficient to significantly reduce the summer drop in $\mathrm{RWC}_{\text {noon }}$. This result may indicate that $\mathrm{RH}$ values achieved with HPM were too low during this period and that a higher RH threshold for fogging is advisable.

\section{Literature Cited}

Augé,R.M.,K.A. Schekel, and R.L. Wample. 1986. Osmotic adjustment in leaves of VAmycorrhizaland nonmycomhizal rose plants in response to drought stress. Plant Physiol. 82:765-770.

Augé,R.M.,K.A. Schekel, and R.L. Wample. 1987. Rose leaf elasticity changes in response to mycorrhizalcolonizationanddroughtacclimation. Physiol.Plant.70: 175-182.

Augé,R.M., A.J.W. Stodola, and B.D. Pennell. 1990. Osmotic and turgor adjustment in Rosa foliage drought-stressed under varying irradiante. J. Amer. Soc. Hort. Sci. 115:661-667.

Ayers, R.S. and D.W. Westcot. 1975. La qualité de l'eau en agriculture. Bul. Food \& Agr. Organization Irr. Drain. 29 
Table 2. Osmotic potential at zero turgor $\left(\Psi_{\pi}^{0}\right)$ and at full turgor $\left(\Psi_{\pi}^{1000}\right)$, average modulus of elasticity $(\varepsilon)$, and relative water content $\left(R W C^{3}\right)$ at zero turgor of rose leaves as affected by electrical conductivity (EC) and high-pressure mist (HPM) vs. shading.

\begin{tabular}{|c|c|c|c|c|c|}
\hline \multicolumn{2}{|c|}{ Treatment $^{z}$} & \multirow{2}{*}{$\begin{array}{c}\Psi_{\pi}^{0} \\
(\mathrm{MPa})\end{array}$} & \multirow{2}{*}{$\begin{array}{l}\Psi_{\pi}^{100} \\
(\mathrm{MPa})\end{array}$} & \multirow{2}{*}{$\begin{array}{c}\varepsilon \\
(\mathrm{MPa})\end{array}$} & \multirow{2}{*}{$\begin{array}{c}\mathrm{RWC}^{0} \\
(\%)\end{array}$} \\
\hline $\mathrm{EC}^{y}$ & Greenhouse & & & & \\
\hline Low & HPM & $-12.3 \pm 0.3 \mathrm{a}^{\mathrm{x}}$ & $-9.5 \pm 0.2 \mathrm{a}$ & $4.9 \pm 0.2 \mathrm{a}$ & $89.8 \pm 0.6 a$ \\
\hline High & & $-12.4 \pm 0.3 \mathrm{a}$ & $-9.7 \pm 0.2 \mathrm{a}$ & $5.4 \pm 0.2 b$ & $90.9 \pm 0.3 \mathrm{a}$ \\
\hline Low & Shaded & $-11.6 \pm 0.3 \mathrm{a}$ & $-9.3 \pm 0.2 \mathrm{a}$ & $5.6 \pm 0.2 b$ & $92.1 \pm 0.4 b$ \\
\hline High & & $-12.1 \pm 0.3 \mathrm{a}$ & $-9.8 \pm 0.2 \mathrm{a}$ & $5.9 \pm 0.2 \mathrm{c}$ & $92.1 \pm 0.3 b$ \\
\hline
\end{tabular}

${ }^{2}$ Data of the five periods for the same treatment were pooled together.

${ }^{y} \mathrm{EC}$ had two levels: low (EC of the drainage $\approx 1.8 \mathrm{mS} \cdot \mathrm{cm}^{-1}$ ), and high $\left(\mathrm{EC}\right.$ of the drainage $\approx 3.8 \mathrm{mS} \cdot \mathrm{cm}^{-1}$ ). ${ }^{x}$ Values are means \pm standard deviations. Mean separation within columns by $\mathrm{F}$ test at $P<0.05$.

Brun, R. and P.H. Tramier. 1988, Culture du rosier sur laine de roche. P.H.M. Rev. Hort. 289:4351.

Bran, R., B. Paris, and I. Hamelin. 1993. Management of the fertilizing irrigation of rose plants grown in greenhouses on rockwool. Adv. Hort. Sci. 7:145-148

Cheung, Y.N.S., M.T. Tyree, and J. Dainty, 1975 Water relations parameters on single leaves obtained in a pressure bomb and some ecological interpretations. Can. J. Bet. 53: 1342- 1346.

De Kreij, C. and T.J.M. Van den Berg. 1990, Nutrient uptake, production and quality of Rosa hybrids in rockwool as affected by electrical conductivity of the nutrient solution,p.519-523. In: M.L. van Beusichem (cd.), Plant nutrition-
Physiology and applications, Kluwer Academic Publishers, Wageningen, The Netherlands,

De Villèle, O. 1972. Besoins en eau des cultures sous serres. Essai de conduite des arrosages en fonction de l'ensoleillement, ActaHort. 35:123130.

Hinckley, T.M., F. Duhme, A.R. Hinckley, and H, Richter. 1980, Water relations in drought hardy shrubs: Osmotic potential and stomatal reactivity. Plant Cell Env. 3: 131-140.

Joly, R.J. and J.B. Zaerr, 1987. Alteration of cellwall water content and elasticity in Douglas-fir during periods of water deficits. Plant Physiol. 83:418422

Jones, MM. and N.C. Turner. 1980, Osmotic adjustment in expanding and fully expanded leaves of sunflower in response to water deficits. Austral. J. Plant Physiol. 7:181-192.

Morgan, J.M. 1980. Osmotic adjustment in the spikelets and leaves of wheat. J. Expt. Bet. 31:655-665.

Morgan, J.M. 1984. Osmoregulation and water stress in higher plants. Ann, Rev. Plant Physiol. 35:299319.

Radin, J.W. 1983. Physiological consequences of cellular water deficits: Osmotic adjustment, p. 267-275. In: J. Grace, E.D. Ford, and P.G. Jarvis (eds.). Limitations to efficient water use in crop production. Amer. Sot. Agron., Madison, Wis.

Rivière, L.M. and H. Nicolas. 1987, Conduite de 1 'irrigation des cultures hors sol sur substrats. Contraintes liées au choix du milieu. Milieux poreux et transfers hydriques. Bul. G.F.H.N, 22; 47-68,

Running, S.W. 1976. Environmental control of leaf water conductance in conifers. Can. J. For. Res. 6:104-112.

Turner, N.C. and M.M. Jones. 1980. Turgor maintenance by osmotic adjustment: A review and evaluation, p. 87-103. In: N.C. Turner and P.J. Kramer (eds.). Adaptation of plants to water and high temperature stress, Wiley, New York.

Urban, L., A, Jaffrin, and A. Chraibi. 1993. Analysis of pressure-volume curves of Rosa hybrida, cv Sonia leaves, J. Expt. Bet. 44:605-613.

Zimmerman, U. 1978, Physics of turgor- and osmoregulation. Ann. Rev. Plant Physiol. 29:12 1148. 